\title{
Erratum to: Risk factors and severity of obstructive sleep apnoea in central European Roma and non-Roma patients referred for a diagnostic polysomnography
}

Zuzana Dorkova - Zuzana Sopkova •

Ruzena Tkacova

Published online: 15 July 2010

(C) Swiss School of Public Health 2010

Erratum to: Int J Public Health

DOI 10.1007/s00038-010-0146-3

The correct title of the original article by Zuzana Dorkova, Zuzana Sopkova, and Ruzena Tkacova is:

Risk factors and severity of obstructive sleep apnoea in central European Roma and non-Roma patients referred for a diagnostic polysomnography

The online version of the original article can be found under doi:10.1007/s00038-010-0146-3.

Z. Dorkova $\cdot$ Z. Sopkova $\cdot$ R. Tkacova $(\bowtie)$

Department of Respiratory Diseases and Tuberculosis,

Medical Faculty, P. J. Safarik University,

L. Pasteur Teaching Hospital, Rastislavova 43,

04190 Košice, Slovakia

e-mail: ruzena.tkacova@upjs.sk 